\title{
Preoperative Neutrophil-Lymphocyte Ratio Is a Predictor of Bowel Obstruction Due to Colorectal Cancer Growth
}

\author{
SEIICHIRO ETO ${ }^{1}$, HIDEJIRO KAWAHARA ${ }^{1}$, TOMO MATSUMOTO ${ }^{1}$, TSUYOSHI HIRABAYASHI $^{1}$, \\ NOBUO OMURA ${ }^{1}$ and KATSUHIKO YANAGA ${ }^{2}$ \\ ${ }^{1}$ Department of Surgery, Nishisaitama-chuo National Hospital, Saitama, Japan; \\ ${ }^{2}$ Department of Surgery, Jikei University School of Medicine, Tokyo, Japan
}

\begin{abstract}
Background: Bowel obstruction is commonly encountered in patients with advanced colorectal cancer; however, the cause of obstruction remains unknown. This study aimed to clarify a predictor of bowel obstruction due to colorectal cancer growth. Materials and Methods: Between January 2005 and December 2013, the medical records of 140 patients with T3 or T4 colorectal cancer who underwent curative resection $(\mathrm{RO})$ at our Hospital were investigated retrospectively. This study consisted of 26 patients with obstructive colorectal cancer (OCC) and 114 patients with nonobstructive colon cancer (non-OCC). Results: Significant differences in clinicopathological factors including age, gender, $T$ category, stage, primary tumor site, tumor diameter, macroscopic type, pathological type, lymphatic invasion, venous invasion, and lymph node metastasis were not observed between the two groups. Preoperative hematological/biochemical parameters including leukocyte count $(p=0.004)$, neutrophil count ( $p=0.003), C$-reactive protein $(C R P)$ level (0.001), and neutrophil-to-lymphocyte ratio $(N L R) \quad(p=0.001)$ were significantly higher in the OCC group than in the non-OCC group. However, a significant difference in lymphocyte count was not observed between the two groups $(p=0.634)$. Significant differences in the levels of the serum tumor markers CEA and CA19-9 were not observed between the two groups. Conclusion: Preoperative NLR seems to be a useful predictor of bowel obstruction due to colorectal cancer growth.
\end{abstract}

Bowel obstruction is encountered in $25-40 \%$ of patients with advanced colorectal cancer $(1,2)$. These patients often require chemotherapy or radiotherapy before tumor resection

Correspondence to: Seiichiro Eto, MD, Department of Surgery, Nishisaitama-chuo National Hospital, 2-1671 Wakasa, Tokorozawashi, Saitama 359-1151, Japan. Tel: +81 429481111, Fax: +81 429481121, e-mail: etoh.sei.ichiro51@gmail.com

Key Words: Bowel obstruction, neutrophil to lymphocyte ratio, colorectal cancer. or palliative treatment. Some studies have reported that elective surgery for obstructive colorectal cancer (OCC) offered better results $(3,4)$. However, other studies indicated that OCC had a poor prognosis even with interventions (1, $5,6)$. Surgical outcomes remain controversial, and the cause of obstruction due to tumor growth remains unknown. This study aimed to clarify a predictor of bowel obstruction due to colorectal cancer growth.

\section{Patients and Methods}

Patients. The Ethics Committee for Biomedical Research of the Nishisaitama Chuo National Hospital Institutional Review Board approved the protocol (12-30). Between January 2005 and December 2013, the medical records of 140 patients with T3 or T4 colorectal cancer who underwent curative resection (R0) at our hospital were investigated retrospectively. This study consisted of 26 patients with OCC and 114 patients with nonobstructive colon cancer (non-OCC). The medical records of all patients were reviewed, and the stages of their tumors were classified according to the Japanese Classification of Colorectal Carcinoma (7). According to this classification, T3 corresponds to the invasion of the subserosa, and T4a corresponds to serosal invasion, excluding direct extension into adjacent structures or organs, which is classified as $\mathrm{T} 4 \mathrm{~b}$.

Hematological/biochemical parameters including the total leucocyte count, serum total protein, albumin level, C-reactive protein (CRP) level, carcinoembryonic antigen (CEA) level, and carbohydrate antigen 19-9 (CA19-9) level were measured before surgery. The preoperative neutrophil to lymphocyte ratio (NLR) was calculated by the number of neutrophils and lymphocytes.

Follow-up after surgery and postoperative chemotherapy. All patients were followed for 5 years, with their serum CEA and CA19-9 levels measured every 3 months, computed tomography (CT) performed every 6 months and colonoscopy performed every 12 months. When we suspected recurrence, CT and positron emission tomography were performed at that time. Patients with stage II or III disease received oral S-1 (Taiho Pharmaceuticals Co., Ltd., Tokyo, Japan) or capecitabine (Xeloda; Hoffmann-La Roche, Basel, Switzerland) for 6 months after surgery. The other patients with stage IV disease received intensive chemotherapy, including oxaliplatin-based regimens [infusional 5-fluorouracil and folinic 
acid plus oxaliplatin (FOLFOX), S-1 (Taiho Pharmaceuticals Co., Ltd., Tokyo, Japan) plus oxaliplatin (SOX), or capecitabine plus oxaliplatin (XELOX)] for six months after surgery, depending on their physical status.

Statistical analysis. Continuous variables are expressed as means and ranges. The Wilcoxon rank sum test was used to compare differences in the continuous variables, and the Chi-square test was used to compare differences in the categorical data. Disease-free survival (DFS) after surgery was examined by the Kaplan-Meier method and by log-rank analysis. A $p$-value less than 0.05 was used to indicate significance. All data were analyzed using the Statistical Package for Social Sciences (SPSS) v. 24.0 (IBM SPSS, Tokyo, Japan).

\section{Results}

Comparison of clinical features between the OCC and the nonOCC groups. The mean age of the OCC group was 72.2 (47-87) years, while that of the non-OCC group was 70.0 (35-89) years. There was no significant difference between the two groups. Significant differences in the other clinicopathological factors including age, gender, $\mathrm{T}$ category, stage, primary tumor site, tumor diameter, macroscopic type, pathological type, lymphatic invasion, venous invasion, and lymph node metastasis were not identified between the two groups (Table I).

Comparison of hematological/biochemical parameters between the OCC and the non-OCC groups. Preoperative hematological/biochemical parameters including leukocyte count, neutrophil count, CRP level, and the NLR of the OCC group, were significantly higher than those of the non-OCC group. However, a significant difference in lymphocyte count was not observed between the two groups. Serum total protein and albumin levels in the OCC group were significantly lower than those in the non-OCC group. Significant differences in the levels of the serum tumor markers CEA and CA19-9, were not observed between the two groups (Table II).

Comparison of DFS between the OCC and non-OCC groups with stage II colorectal cancer. The 3-year DFS of 14 patients with OCC at stage II was $91.7 \%$, whereas that of 49 patients with non-OCC at stage II was $87.2 \%$, which was not a significant difference (Figure 1).

Comparison of DFS between the OCC and non-OCC groups with stage III colorectal cancer. The 3-year DFS of 9 patients with OCC at stage III was $58.3 \%$, whereas that of 54 patients with non-OCC at stage III was $68.0 \%$, which was not a significant difference (Figure 2).

\section{Discussion}

Many researchers have accepted that inflammation is related to not only carcinogenesis, but also to cancer progression (8,
Table I. Comparison of clinicopathological features between the two groups.

\begin{tabular}{|c|c|c|c|}
\hline Characteristic & $\begin{array}{l}\text { OCC } \\
(n=26)\end{array}$ & $\begin{array}{c}\text { non-OCC } \\
(\mathrm{n}=114)\end{array}$ & $p$-Value \\
\hline Mean age (range), years & $72.2(57-87)$ & $70.0(35-89)$ & 0.475 \\
\hline Gender, $\mathrm{n}(\%)$ & & & 0.048 \\
\hline Male & $19(73)$ & $57(50)$ & \\
\hline Female & $7(27)$ & $57(50)$ & \\
\hline $\mathrm{T}$ category & & & 0.206 \\
\hline $\mathrm{T} 3, \mathrm{n}(\%)$ & $17(65)$ & $89(78)$ & \\
\hline $\mathrm{T} 4, \mathrm{n}(\%)$ & $9(35)$ & $25(22)$ & \\
\hline Stage & & & 0.498 \\
\hline $\mathrm{II}, \mathrm{n}(\%)$ & $14(54)$ & $49(43)$ & \\
\hline III, n (\%) & $9(35)$ & $54(47)$ & \\
\hline $\mathrm{IV}, \mathrm{n}(\%)$ & $3(11)$ & $11(10)$ & \\
\hline Primary tumor site & & & 0.064 \\
\hline Colon, $\mathrm{n}(\%)$ & $22(85)$ & $75(66)$ & \\
\hline Rectum, n (\%) & $4(15)$ & $39(34)$ & \\
\hline Tumor diameter (range), mm & $54.7(20-120)$ & $55.4(15-200)$ & 0.877 \\
\hline Macroscopic type of tumor & & & 0.372 \\
\hline $\mathrm{I}, \mathrm{n}(\%)$ & $2(8)$ & $3(2)$ & \\
\hline $\mathrm{II}, \mathrm{n}(\%)$ & $19(73)$ & $98(86)$ & \\
\hline III, n (\%) & $3(11)$ & $9(8)$ & \\
\hline $\mathrm{IV}, \mathrm{n}(\%)$ & $2(8)$ & $4(4)$ & \\
\hline Pathological type of tumor & & & 0.592 \\
\hline Well dif. adenoca., n (\%) & $5(19)$ & $24(21)$ & \\
\hline Moderately dif. Adenoca., n (\%) & $19(73)$ & $79(70)$ & \\
\hline Poorly dif. adenoca., n (\%) & $0(0)$ & $6(5)$ & \\
\hline Others, $\mathrm{n}(\%)$ & $2(8)$ & $5(4)$ & \\
\hline Lymphatic invasion & & & 0.516 \\
\hline Present, n (\%) & $15(58)$ & $56(49)$ & \\
\hline Abscent, n (\%) & $11(42)$ & $58(51)$ & \\
\hline Venous invasion & & & 0.798 \\
\hline Present, n (\%) & $5(19)$ & $26(23)$ & \\
\hline Abscent, n (\%) & $21(81)$ & $88(77)$ & \\
\hline Lymph node metastasis & & & 0.389 \\
\hline Present, n $(\%)$ & $12(46)$ & $64(56)$ & \\
\hline Abscent, n (\%) & $14(54)$ & $50(44)$ & \\
\hline
\end{tabular}

OCC: Obstructive colorectal cancer, dif. adenoca.: differentiated adenocarcinoma.

9). Tumor growth is promoted by preinflammatory cytokines and chemokines that are released from tumor-infiltrating leukocytes, which are themselves stimulated by the tumor. Therefore, inflammatory markers, such as CRP and interleukin-6 (IL-6), are elevated in various types of malignant diseases and closely related to the prognosis of patients with those malignant diseases (10-12). Total leukocyte and neutrophil counts have historically been used as infection markers. The NLR, which is defined by the neutrophil count divided by the lymphocyte count, is also an inflammatory biomarker. Several studies have reported that an elevated NLR, a simple index of systemic inflammation, is associated with poor prognosis in patients with various types of malignant diseases (13-21). 


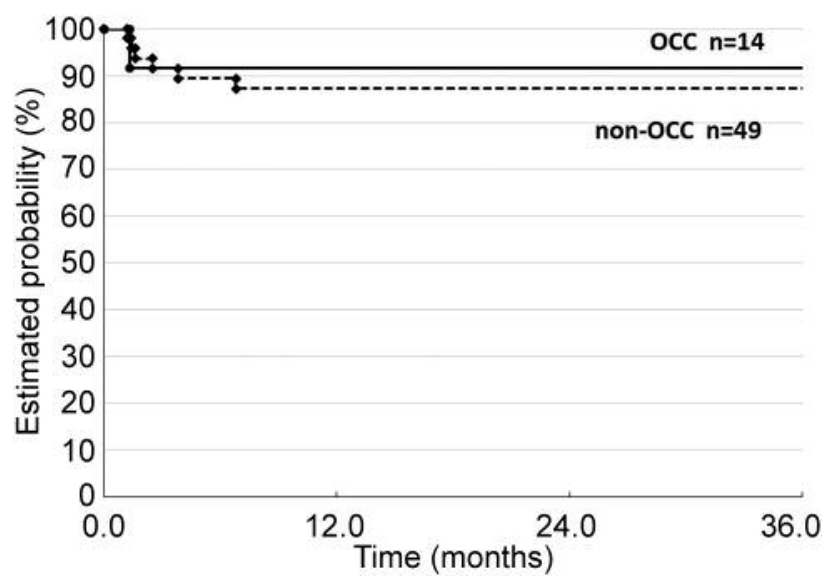

Figure 1. Comparison of DFS between the OCC and non-OCC groups in stage II. No significant difference was identified between the two groups.

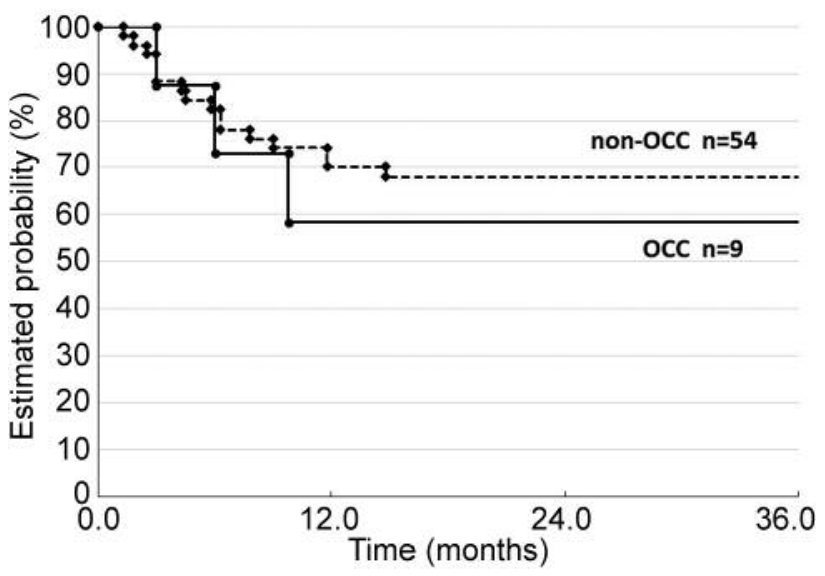

Figure 2. Comparison of DFS between the OCC and non-OCC groups in stage III. No significant difference was identified between the two groups.

Table II. Comparison of hematological/biochemical parameters between the two groups.

\begin{tabular}{|c|c|c|c|}
\hline Characteristic & OCC $(n=26)$ & non-OCC $(\mathrm{n}=114)$ & $p$-Value \\
\hline Leucocyte count, mean (range) $/ \mathrm{mm}^{3}$ & $7790.9(4000-12100)$ & $6613.5(2800-14500)$ & 0.004 \\
\hline Neutropil count, mean (range) $/ \mathrm{mm}^{3}$ & $5642.3(2320-8712)$ & $4458.2(644-12180)$ & 0.003 \\
\hline Lymphocyte counts, mean (range) $/ \mathrm{mm}^{3}$ & $1629.3(677-2800)$ & $1797.6(558-5080)$ & 0.634 \\
\hline Neutrophil to lymphocyte ratio, (range) & $3.9(1.7-6.8)$ & $2.7(0.4-7.6)$ & 0.001 \\
\hline Total protein, mean (range) $\mathrm{g} / \mathrm{dl}$ & $6.3(4.1-8.6)$ & $6.9(5.7-8.6)$ & 0.024 \\
\hline Albumin, mean (range) g/dl & $3.5(1.9-5.4)$ & $3.9(2.8-5.0)$ & 0.009 \\
\hline C-reactive protein, mean (range) U/l & $3.0(0.0-33.0)$ & $0.94(0.0-7.9)$ & 0.001 \\
\hline Serum CEA & & & 0.665 \\
\hline Normal, n (\%) & $14(54)$ & $54(47)$ & \\
\hline$>5.0 \mathrm{ng} / \mathrm{ml}, \mathrm{n}(\%)$ & $12(46)$ & $60(53)$ & \\
\hline Serum CA19-9 & & & 0.609 \\
\hline Normal, n $(\%)$ & $19(73)$ & $89(78)$ & \\
\hline$>37.0 \mathrm{U} / \mathrm{ml}, \mathrm{n}(\%)$ & $7(27)$ & $25(22)$ & \\
\hline
\end{tabular}

OCC: Obstructive colorectal cancer; CEA: carcinoembryonic antigen; CA19-9: carbohydrate antigen 19-9.

In this study, the inflammatory marker levels, leucocyte count, neutrophil count, CRP level, and NLR of the OCC group were significantly higher than those of the non-OCC group; however, significant differences in lymphocyte counts were not observed between the two groups. This is a specific phenomenon of malignant diseases that distinguishes it from inflammatory diseases caused by infection. Therefore, the NLR seems to be a more useful predictor than CRP level in malignant diseases. We found that the NLR was associated with bowel obstruction due to colorectal cancer growth. However, a large-scale prospective or retrospective study is needed to clarify this issue.

Serum albumin levels have been studied as part of the Glasgow Prognostic Score (GPS), which is based on a combination of albumin and CRP levels. Several reports have revealed that the GPS has a prognostic value in patients with advanced colorectal cancer $(22,23)$. In the present study, the serum total protein and albumin levels of the OCC group were significantly lower than those of the non-OCC group; however, these factors did not contribute to their outcomes. Previous studies have reported that patients with OCC have a significantly worse oncological outcome than patients with non-OCC $(1,5,6)$. A significant difference in the 3-year DFS was not observed between the OCC and nonOCC groups with either stage II or III disease in our study. One reason for a good outcome might be the performance of complete tumor resection (R0) and extended D2/D3 lymph node dissection, the so-called Japanese standard lymph node 
dissection. Complete tumor resection is required for good outcomes even if patients have OCC (24).

In conclusion, preoperative NLR seems to be a useful predictor of bowel obstruction due to colorectal cancer growth.

\section{Conflicts of Interest}

The Authors declare that there are no conflicts of interest regarding this study.

\section{Authors' Contributions}

All Authors performed operations, analyzed the data of patients regarding their clinical features, and have been involved in drafting the manuscript. KY had given final approval of the version to be published. All Authors read and approved the final manuscript.

\section{References}

1 Alese OB, Kim S, Chen Z, Owonikoko TK and El-Rayes BF: Management patterns and predictors of mortality among US patients with cancer hospitalized for malignant bowel obstruction. Cancer 121: 1772-1778, 2015. PMID: 25739854. DOI: $10.1002 /$ cncr.29297

2 Baines M, Oliver DJ and Carter RL: Medical management of intestinal obstruction in patients with advanced malignant disease. A clinical and pathological study. Lancet 2: 990-993, 1985. PMID: 2414614.

3 Lilley EJ, Scott JW, Goldberg JE, Cauley CE, Temel JS, Epstein AS, Lipsitz SR, Smalls BL, Haider AH, Bader AM, Weissman JS and Cooper Z: Survival, healthcare utilization, and end-oflife care among older adults with malignancy-associated bowel obstruction: comparative study of surgery, venting gastrostomy, or medical management. Ann Surg 267(4): 692-699, 2018. PMID: 28151799. DOI: 10.1097/SLA.0000000000002164

4 Jiménez-Pérez J, Casellas J, García-Cano J, Vandervoort J, García-Escribano OR, Barcenilla J, Delgado AA, Goldberg P, Gonzalez-Huix F, Vázquez-Astray E and Meisner S: Colonic stenting as a bridge to surgery in malignant large-bowel obstruction: a report from two large multinational registries. Am J Gastroenterol 106: 2174-2180, 2011. PMID: 22085816. DOI: 10.1038/ajg.2011.360

5 Legendre H, Vanhuyse F, Caroli-Bosc FX and Pector JC: Survival and quality of life after palliative surgery for neoplastic gastrointestinal obstruction. Eur J Surg Oncol 27: 364-367, 2001. PMID: 11417981. DOI: 10.1053/ejso.2001.1120

6 Chakraborty A, Selby D, Gardiner K, Myers J, Moravan V and Wright F: Malignant bowel obstruction: natural history of a heterogeneous patient population followed prospectively over two years. J Pain Symptom Manag 41: 412-420, 2011. PMID: 21131167. DOI: 10.1016/j.jpainsymman.2010.05.007

7 Japanese Society for Cancer of the Colon and Rectum: Japanese Classification of Colorectal Carcinoma, 2nd English edn. Tokyo: Kanehara Co. Ltd; 2009.

8 Coussens LM and Werb Z: Inflammation and cancer. Nature 420(6917): 860-867, 2002. PMID: 12490959. DOI: 10.1038/ nature 01322
9 Vakkila J and Lotze MT: Inflammation and necrosis promote tumour growth. Nat Rev Immunol 4(8): 641-648, 2004. PMID: 15286730. DOI: $10.1038 /$ nri 1415

10 Crumley AB, McMillan DC, McKernan M, Going JJ, Shearer $\mathrm{CJ}$ and Stuart RC: An elevated C-reactive protein concentration, prior to surgery, predicts poor cancer-specific survival in patients undergoing resection for gastro-oesophageal cancer. Br J Cancer 94(11): 1568-1571, 2006. PMID: 16685271. DOI: 10.1038/ sj.bjc. 6603150

11 Leitch EF, Chakrabarti M, Crozier JE, McKee RF, Anderson JH, Horgan PG and McMillan DC: Comparison of the prognostic value of selected markers of the systemic inflammatory response in patients with colorectal cancer. Br J Cancer 97(9): 1266-1270, 2007. PMID: 17923866. DOI: 10.1038/sj.bjc.6604027

12 Pine SR, Mechanic LE, Enewold L, Chaturvedi AK, Katki HA, Zheng YL, Bowman ED, Engels EA, Caporaso NE and Harris CC: Increased levels of circulating interleukin 6 , interleukin $8, \mathrm{C}-$ reactive protein, and risk of lung cancer. J Natl Cancer Inst 103(14): 1112-1122, 2010. PMID: 21685357. DOI: 10.1093/ jnci/djr216

13 Shimada H, Takiguchi N, Kainuma O, Soda H, Ikeda A, Cho A, Miyazaki A, Gunji H, Yamamoto $H$ and Nagata M: High preoperative neutrophil-lymphocyte ratio predicts poor survival in patients with gastric cancer. Gastric Cancer 13: 170-176, 2010. PMID: 20820986 DOI: 10.1007/s10120-010-0554-3

14 Chua W, Charles KA, Baracos VE and Clarke SJ: Neutrophil/ lymphocyte ratio predicts chemotherapy outcomes in patients with advanced colorectal cancer. Br J Cancer 104: 1288-1295, 2011. PMID: 21448173. DOI: 10.1038/bjc.2011.100

15 Wang GY, Yang Y, Li H, Zhang J, Jiang N, Li MR, Zhu HB, Zhang Q and Chen GH: A scoring model based on neutrophil to lymphocyte ratio predicts recurrence of HBV-associated hepatocellular carcinoma after liver transplantation. PLoS One 6: e25295, 2011. PMID: 21966488. DOI: 10.1371/ journal. pone. 0025295

16 Wang DS, Luo HY, Qiu MZ, Wang ZQ, Zhang DS, Wang FH, $\mathrm{Li} \mathrm{YH}$, and $\mathrm{Xu} \mathrm{RH}$ : Comparison of the prognostic values of various inflammation based factors in patients with pancreatic cancer. Med Oncol 29: 3092-3100, 2012. PMID: 22476808. DOI: $10.1007 / \mathrm{s} 12032-012-0226-8$

17 Pichler M, Hutterer GC, Stoeckigt C, Chromecki TF, Stojakovic T, Golbeck S, Eberhard K, Gerger A, Mannweiler S, Pummer K and Zigeuner R: Validation of the pre-treatment neutrophillymphocyte ratio as a prognostic factor in a large European cohort of renal cell carcinoma patients. Br J Cancer 108(4): 901907, 2013. PMID: 23385728. DOI: 10.1038/ bjc.2013.28

18 Stotz M, Gerger A, Eisner F, Szkandera J, Loibner H, Ress AL, Kornprat P, AlZoughbi W, Seggewies FS, Lackner C, Stojakovic $\mathrm{T}$, Samonigg $\mathrm{H}$, Hoefler $\mathrm{G}$ and Pichler $\mathrm{M}$ : Increased neutrophillymphocyte ratio is a poor prognostic factor in patients with primary operable and inoperable pancreatic cancer. Br J Cancer 109: 416-421, 2013. PMID: 23799847. DOI: 10.1038/ bjc. 2013.332

19 Motomura T, Shirabe K, Mano Y, Muto J, Toshima T, Umemoto Y, Fukuhara T, Uchiyama H, Ikegami T, Yoshizumi T, Soejima $\mathrm{Y}$ and Maehara Y: Neutrophil-lymphocyte ratio reflects hepatocellular carcinoma recurrence after liver transplantation via inflammatory microenvironment. J Hepatol 58: 58-64, 2013. PMID: 22925812. DOI: 10.1016/ j.jhep.2012.08.017

20 Yoshizumi T, Ikegami T, Yoshiya S, Motomura T, Mano Y, Muto J, Ikeda T, Soejima Y, Shirabe K and Maehara Y: Impact of 
tumor size, number of tumors and neutrophil-to-lymphocyte ratio in liver transplantation for recurrent hepatocellular carcinoma. Hepatol Res 43: 709-716, 2013. PMID: 23190306. DOI: $10.1111 /$ hepr.12016

21 Gürol G, Çiftci İH, Terizi HA, Atasoy AR, Ozbek A and Köroğlu M: Are there standardized cutoff values for neutrophillymphocyte ratios in bacteremia or sepsis? J Microbiol Biotechnol 25(4): 521-525, 2015. PMID: 25341467.

22 Ishizuka M, Nagata $H$, Takagi $K$, Horie $T$ and Kubota $K$ : Inflammation-based prognostic score is a novel predictor of postoperative outcome in patients with colorectal cancer. Ann Surg 246: 1047-1051, 2007. PMID: 18043109. DOI: 10.1097/ SLA.0b013e3181454171

23 McMillan DC, Crozier JE, Canna K, Angerson WJ and McArdle CS: Evaluation of an inflammation-based prognostic score (GPS) in patients undergoing resection for colon and rectal cancer. Int J Colorectal Dis 22: 881-886, 2007. PMID: 17245566. DOI: $10.1007 / \mathrm{s} 00384-006-0259-6$
24 Atsushi I, Mitsuyoshi O, Kazuya Y, Syuhei K, Noriyuki K, Masashi M, Akira W, Kentaro S, Nobuyuki K, Natsuko S, Jun W, Yasushi I, Chikara K and Itaru E: Long-term outcomes and prognostic factors of patients with obstructive colorectal cancer: A multicenter retrospective cohort study. World J Gastroenterol 22(22): 5237-5245, 2016. PMID: 27298566. DOI: 10.3748/ wjg.v22.i22.5237
Received April 5, 2019

Revised May 13, 2019

Accepted May 17, 2019 